\title{
Infection Risk of Lumbar Epidural Injection in the Operating Theatre Prior to Lumbar Fusion Surgery
}

Peng Li

Xiuwei Hou

Lifeng Gao

Xiaochen Zheng

Department of Orthopedics, The Second Affiliated Hospital of Luohe Medical College, Luohe, Henan 462300, People's Republic of China
This article was published in the following Dove Press journal: Journal of Pain Research

Purpose: To determine the association between preoperative lumbar epidural injections (LEIs) in the operating theater (OR) and the occurrence of surgical site infection (SSI) after posterior lumbar instrumented fusion surgery.

Methods: This study was performed from January 2015 to September 2019. We enrolled 2312 patients who underwent lumbar surgery without LEIs (control group) and 469 patients who underwent lumbar surgery after LEIs in the OR. We further separated the patients by the time interval between the LEIs and surgery: 1) for the 0-1 M group, lumbar surgery was performed within 1 month after the LEIs, and 2) for the $>1 \mathrm{M}$ group, it was performed more than 1 month after the LEIs.

Results: The postoperative infection rate in the $0-1 \mathrm{M}$ group was considerably higher than that in the control group ( $p=0.0101$ ). We further subdivided the $0-1 \mathrm{M}$ and $>1 \mathrm{M}$ groups into four subgroups: a) the $0-1 \mathrm{MNS}$ group included patients in the $0-1 \mathrm{M}$ group who did not receive steroids; b) the $0-1$ MS group who received steroids; c) the $>1$ MNS group included patients in the $>1 \mathrm{M}$ group who did not receive steroids; d) the $>1$ MS group who received steroids. The postoperative infection rate in the $0-1$ MS subgroup was considerably higher than that in the control group $(p=0.0018)$. However, the infection rate was lower in the $>1$ MS subgroup ( $p=0.1650)$. There were no statistically significant differences in the postoperative infection rate between the control group and the two non-steroid groups ( $0-1 \mathrm{MNS}$ group, $p=0.4961 ; 1$ MNS group, $p=0.7381$ ).

Conclusion: The administration of LEIs without steroids in the OR before lumbar instrumented fusion does not significantly increase patients' risk of postoperative infection. We recommend avoiding steroid injections administered within 1 month before lumbar instrumented fusion.

Keywords: epidural injections, postoperative complications, spine puncture, surgical wound infection

\section{Introduction}

Low back pain, which leads to limitations in activity and the loss of productivity, is one of the major health care issues worldwide. Almost everyone suffers from low back pain at some point in their lives. ${ }^{1}$ Low back pain and its related radiculopathies are one of the most common reasons individuals in the US seek medical care. ${ }^{2}$ Lumbar disc herniation, degenerative disc disease, and facet joint dysfunction are common causes of low back pain. ${ }^{3}$ Lumbar epidural injections (LEIs) are commonly used to treat chronic low back pain. Some studies have shown that local
Correspondence: Xiuwei Hou Email HouxiuweilII@I63.com 
anesthetics or steroid injections can effectively alleviate low back pain by suppressing inflammatory mediators and increasing blood flow to ischemic nerve roots. ${ }^{1,4-6}$ However, another study reported that epidural steroid injections can only provide short-term rather than longterm pain relief. ${ }^{7}$ LEI procedures can be used for diagnostic or therapeutic purposes prior to lumbar surgical interventions.

Although a LEI is generally considered a safe procedure, it is associated with several complications, such as hematomas, allergic reactions, and infections. ${ }^{89}$ Infections after lumbar surgery have a considerable impact on recovery. The infection rate after posterior lumbar instrumented surgical procedures is approximately $3 \% .^{10} \mathrm{~A}$ recent nationwide database study reported that patients who undergo lumbar fusion $<3$ months after LEIs may suffer from a higher postoperative infection rate. ${ }^{11}$ In addition, the US Food and Drug Administration has not approved the injection of corticosteroids into the epidural space due to infections. ${ }^{5}$ However, Seavey et $\mathrm{al}^{12}$ reported that preoperative LEIs do not increase the postoperative infection rate. These conflicting data suggest that the true effect of preoperative LEIs on postoperative infection remains unclear. The purpose of this study was to assess the association between preoperative LEIs in the operating theatre (OR) and the incidence of SSI after posterior lumbar instrumented fusion surgery.

\section{Methods}

\section{Patient Selection}

A comparative prospective study including a series of patients who underwent instrumented posterior lumbar fusion for degenerative disc disease in our medical center after January 2015 was performed after the institutional review board at our hospital approved the study. The inclusion criteria were a diagnosis of lumbar disc herniation or another degenerative lumbar spine disease confirmed by radiological examination; predominantly chronic low back pain associated with radicular symptoms lasting more than 6 months; and participation in medical therapy or physical rehabilitation for more than 3 months without improvement. Patients who had a history of a minimally invasive procedure not performed in the OR, lumbar surgery, or a spinal infection and those who did not attend a follow-up after the procedure were excluded. This study was approved by the ethical committee of The Second Affiliated Hospital of Luohe Medical College
(2014-11-01), written informed consent was obtained from the participants, and the study was performed according to institutional guidelines and the Declaration of Helsinki.

Through September 2019, a total of 3212 patients underwent lumbar instrumented fusion in our medical center. A total of 2781 patients who met the inclusion criteria were enrolled in our study. There were 1665 female and 1116 male patients, with an average age of $60.5 \pm 6.6$ years (range from 47 to 78 years). A total of 2312 patients who underwent lumbar instrumented fusion without LEIs were included in the control group, while the other 469 patients had undergone LEIs in the OR before lumbar instrumented fusion. According to a previous report, patients who underwent lumbar surgery within 1 month after LEIs had the highest infection rate. ${ }^{11}$ Therefore, we subdivided the patients in our study by the time interval between the LEIs and surgery: 1) the $0-1 \mathrm{M}$ group included patients for whom lumbar surgery performed within 1 month after LEIs, and 2) the $>1 \mathrm{M}$ group include those for whom surgery was performed more than 1 month after the LEIs.

All the LEI procedures were performed under C-arm in a sterile OR. The patients were placed in a comfortable prone position, and the skin was sterilized. After local anesthesia, the segmental level was identified, and the tip of the needle was placed in the lower third foramen under fluoroscopy. Lidocaine with or without steroids was administered. A few weeks after the LEIs (usually 1 to 12 weeks), posterior lumbar instrumented fusion was performed. All the lumbar surgeries were performed by two senior specialists (X.H. and L.P.). The patients were followed up for more than 6 months after posterior lumbar fusion to determine whether they developed a surgical site infection related to the operation. ${ }^{13}$

\section{Statistical Analysis}

Statistical analyses were performed using Prism software for macOS (version 8.2.1). Comparisons between groups were performed by Student's $t$-test, the chi-squared test, or Fisher's exact test. We also calculated the odds ratio and $95 \%$ confidence intervals. $p<0.05$ was considered to indicate statistical significance.

\section{Results}

There were 469 (16.9\%) patients (282 females and 187 males) in the injection group and $2312(83.1 \%)$ patients (1383 females and 929 males) in the control group. The average age of the patients was $60.5 \pm 5.8$ years for the 
Table I Preoperative and Intraoperative Characteristics and Clinical Outcomes

\begin{tabular}{|l|l|l|l|l|l|}
\hline \multirow{2}{*}{ Characteristics } & \multicolumn{2}{|l|}{ Injection Group (N = 469) } & \multirow{2}{*}{ Control Group (N = 23 I 2) } & \multicolumn{2}{l|}{ p value } \\
\cline { 2 - 3 } & 0-IM Group (N = 258) & > I M Group (N = 2 I I) & & 0-IM Group & $>$ I M Group \\
\hline Age* (yr) & $60.4 \pm 5.9$ & $60.6 \pm 5.8$ & $59.4 \pm 6.8$ & 0.373 & 0.2638 \\
Female sex (\%) & 62.0 & 57.8 & 59.8 & 0.4944 & 0.57 II \\
BMF (kg/m²) & $28.0 \pm 5.5$ & $26.27 \pm 3.8$ & $27.4 \pm 4.2$ & 0.4017 & 0.2623 \\
Diabetes mellitus (\%) & 12.8 & 13.3 & 13.8 & 0.7034 & 0.9169 \\
Smoking history (\%) & 11.2 & 13.7 & 12.9 & 0.4916 & 0.7478 \\
Blood loss* (mL) & $364.2 \pm 107.0$ & $377.1 \pm 108.6$ & $380.0 \pm 99.1$ & 0.3337 & 0.8652 \\
No. of levels fused* & $3.5 \pm 1.0$ & $3.3 \pm 0.9$ & $3.2 \pm 0.9$ & 0.2064 & 0.6776 \\
\hline
\end{tabular}

Note: *The values are given as the mean and the standard deviation.

Abbreviation: BMI, body mass index.

injection group (range, 48 to 78 ) and $59.4 \pm 6.8$ years for the control group (range, 47 to 78 ). The 469 patients were divided by the time interval between the LEIs and lumbar surgery. The $0-1 \mathrm{M}$ group included patients with a time interval of less than 1 month $(258,55.01 \%)$, and the $>1$ $\mathrm{M}$ group included patients with a time interval of more than 1 month $(211,44.99 \%)$. The patient characteristics are shown in Table 1. All these patients underwent posterior lumbar decompression with pedicle screw fixation and bone graft fusion. No significant differences were found between the $0-1 \mathrm{M} />1 \mathrm{M}$ group and the control group in blood loss or the number of fused levels $(p>0.05)$. The postoperative infection rate for the $0-1 \mathrm{M}$ and $>1 \mathrm{M}$ groups are presented in Table 2. The infection rate of the $0-1 \mathrm{M}$ group was $6.98 \%$ (18/258), which was higher than that of the control group $(3.51 \%, 81 / 2312)$ (odds ratio (OR) 1.99, range 1.21-3.22, $p=0.0101)$. In the $>1 \mathrm{M}$ group, the infection rate decreased to $5.21 \%(11 / 211)$, and there was no significant difference between the control group and the $>1 \mathrm{M}$ group.

We subdivided the $0-1 \mathrm{M}$ group and $>1 \mathrm{M}$ group into non-steroid (NS) and steroid (S) subgroups according to whether the patients received a steroid injection. We did not find an significant differences between the 0-1 MNS

Table 2 Postoperative Infection Rate in the Injection Group versus the Control Group

\begin{tabular}{|c|c|c|c|}
\hline \multirow[t]{2}{*}{ Variable } & \multicolumn{2}{|c|}{ Injection Group } & \multirow{2}{*}{$\begin{array}{l}\text { Control } \\
\text { Group }\end{array}$} \\
\hline & $\begin{array}{l}0-I M \\
\text { Group }\end{array}$ & $\begin{array}{l}>1 M \\
\text { Group }\end{array}$ & \\
\hline No. of individuals & 258 & 211 & 2312 \\
\hline No. of postoperative infection (\%) & $18(6.98)$ & II (5.2I) & $81(3.51)$ \\
\hline Odds ratio $(95 \% \mathrm{Cl})$ & $\begin{array}{l}1.99 \\
(1.21-3.22)\end{array}$ & $\begin{array}{l}1.51 \\
(0.816-2.80)\end{array}$ & NA \\
\hline$p$ value & $0.0101^{\dagger}$ & 0.2458 & NA \\
\hline
\end{tabular}

Note: 'Significant. (patients in the $0-1 \mathrm{M}$ group who did not receive a steroid injection), $>1$ MNS (patients in the $>1 \mathrm{M}$ group who did not receive a steroid injection), and $>1$ MS (patients in the $0-1$ months group who received a steroid injection) subgroups and the control group $(p=0.4961,0.7381$, and 0.1650 , respectively). However, the infection rate was much higher in the 0-1 MS subgroup (patients in the $0-1 \mathrm{M}$ group who received a steroid injection) $(p=$ 0.0018 ) than in the control group (Figure 1).

\section{Discussion}

There are some studies on the association between LEIs and the infection rate after spine surgery. However, these existing studies reported conflicting results. ${ }^{10,11,14,15}$ Recently, Signla et $\mathrm{al}^{11}$ found that the risk of postoperative infection significantly increased when the LEIs were performed within 1 month prior to nonfusion lumbar decompression $(p<0.0001)$. The results of our study showed that the administration of LEIs within 1 month before lumbar spinal instrumentation fusion significantly increased the incidence of SSI, which is consistent with the results of the study by Signla et al. ${ }^{11}$ However, we found that the administration of LEIs without steroids before lumbar spinal instrumentation fusion did not increase the odds of SSI in either the 0-1 MNS group or the $>1$ MNS group ( $p=0.4961$ and 0.7381 , respectively).

The exact mechanistic link between LEIs and postoperative infection remains unknown. Potential etiologies may be direct contamination, skin flora inoculation or immunosuppression of steroids. For patients undergoing total knee arthroplasty (TKA), intra-articular injections should be avoided within 3 months prior to surgery. ${ }^{16}$ Most intra-articular injections are performed in a therapeutic department, not in the OR. However, all the LEIs in our prospective study were performed in the OR, 


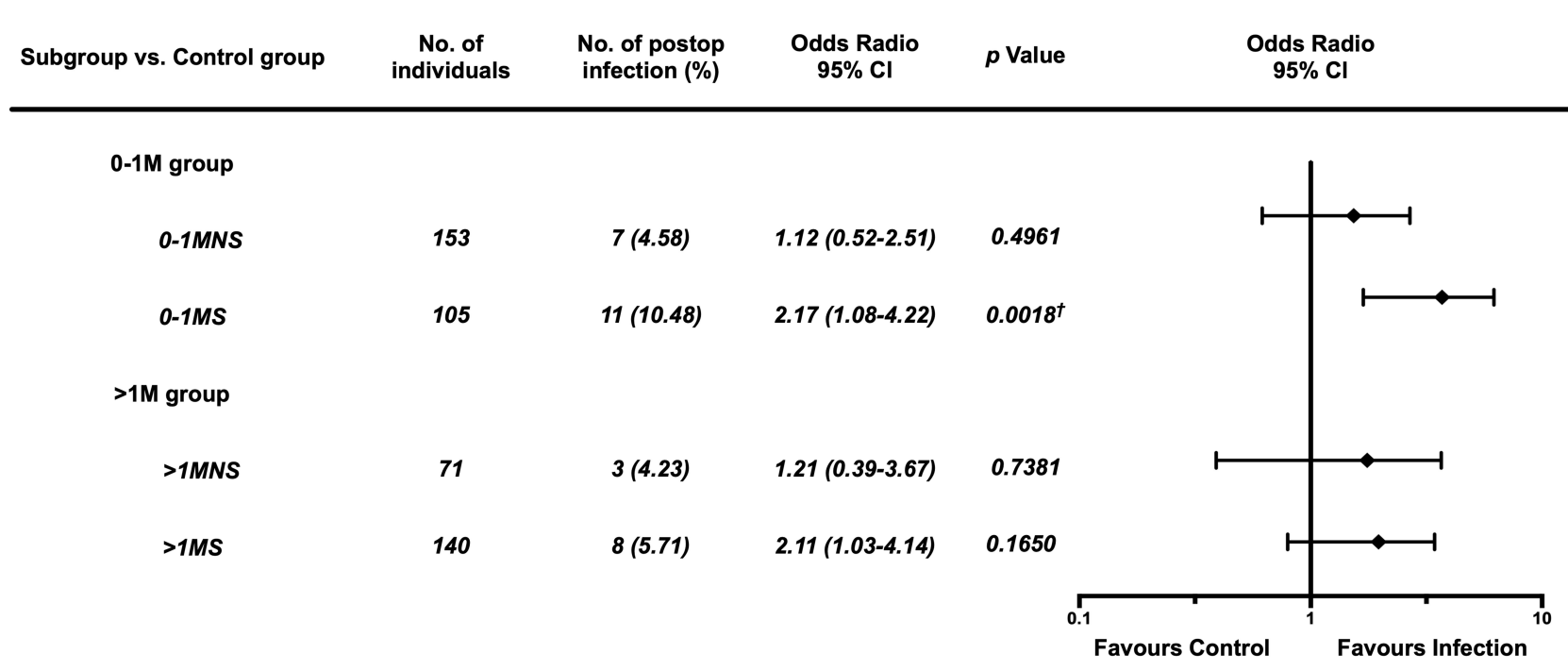

Figure I Forest plot of the postoperative infection rate of the 0-I MNS, 0-I MS, >I MNS, and >I MS subgroups compared with the control group. †p < 0.05.

which has a much cleaner environment than a does a therapeutic department. Thus, the administration of LEIs in the OR could significantly reduce the introduction of exogenous bacteria into the spinal space. When the effects of the steroid were excluded, the risk of an infection was not increased in either non-steroid group (0-1 MNS and $>1$ MNS). Thus, if LEIs without steroids are administered for diagnostic purposes in the OR, there is no need to wait 3 months before performing lumbar surgery, such as TKA or THA. ${ }^{16,17}$

However, corticosteroids are a type of antiinflammatory drug used to treat autoimmune diseases, and the topical administration of corticosteroids might decrease patients' immune response following surgery. Thus, having received a steroid injection is a risk factor for local infection, such as abscess, discitis, and meningomyelitis. ${ }^{18-20}$ Although there is a low infection rate following epidural steroid injection, the infection can be magnified by lumbar instrumentation fusion. It has been reported that steroids can dysregulate the host inflammatory response to pathogen exposure and tissue injury, which results in an increased susceptibility to postoperative infection. ${ }^{14,21}$ In our study, the injection of steroids within 1 month before lumbar spinal instrumentation fusion significantly increased the incidence of SSI (10.48\%, $p=0.0018)$. This increased level of risk decreases as the time interval between LEIs and spinal surgery increases. The administration of LEIs with steroids more than 1 month prior to lumbar spinal instrumentation fusion did not lead to a significant increase in SSI $(p=0.1650)$. A meta-analysis of 14 randomized controlled trials showed that the effectiveness of steroids was significantly superior to that of saline only and local anesthetics at 1 month, and the efficacy of steroids along with the associated adverse effects diminished after 1 month. ${ }^{22}$ This finding explains why the postoperative infection rate significantly diminished after 1 month prior to lumbar fusion. To explore the mechanism of infection associated with topical steroid application, the pharmacokinetics of LEIs with steroids should be studied further.

Another reason for the inconsistency between our results and those of other reports ${ }^{11,14}$ is that we included longer follow-up periods. Most postoperative infections occur between three days and three months after lumbar surgery, but they can take as long as six months to develop, especially after instrumented spinal fusion. ${ }^{23}$ All the patients in our study were followed up for more than 6 months postoperatively, and no patients were lost to follow-up.

This study had some limitations. First, all the injectiontiming groups were relatively small, including fewer than 20 patients, and were likely underpowered to detect small but statistically significant differences between groups. Second, our study population was only limited to patients enrolled in a single institution; thus, it may not reflect the general population. Third, the observer biases cannot be avoided, because both the patients and doctors know the treatment methods.

In conclusion, it is relatively safe to perform LEIs in an OR. However, steroids may significantly increase the incidence of infection. There is a potential increased risk of postoperative infection in patients who undergo preoperative LEIs with steroids within 1 month prior to lumbar 
instrumented fusion. We recommend waiting more than 1 month after the steroid injection to perform lumbar surgery.

\section{Data Sharing Statement}

The data that support the findings of this study are available from the corresponding author upon reasonable request.

\section{Author Contributions}

All authors made a significant contribution to the work reported, whether that is in the conception, study design, execution, acquisition of data, analysis and interpretation, or in all these areas; took part in drafting, revising or critically reviewing the article; gave final approval of the version to be published; have agreed on the journal to which the article has been submitted; and agree to be accountable for all aspects of the work.

\section{Disclosure}

The authors declare no conflicts of interest for this work.

\section{References}

1. Urits I, Burshtein A, Sharma M, et al. Low back pain, a comprehensive review: pathophysiology, diagnosis, and treatment. Curr Pain Headache Rep. 2019;23(3):23. doi:10.1007/s11916-019-0757-1

2. Pakpoor J, Raad M, Harris A, et al. Diagnostic imaging use for the initial evaluation of low back pain by primary care providers in the United States: 2011-2016. J Am Coll Radiol. 2019;16(11):1522-1527. doi:10.1016/j.jacr.2019.04.015

3. Popescu A, Lee H. Neck pain and lower back pain. Med Clin North Am. 2020;104(2):279-292. doi:10.1016/j.mcna.2019.11.003

4. Manchikanti L, Singh V, Cash KA, et al. Preliminary results of a randomized, equivalence trial of fluoroscopic caudal epidural injections in managing chronic low back pain: part 2-Disc herniation and radiculitis. Pain Physician. 2008;11(6):801-815.

5. Rivera CE. Lumbar epidural steroid injections. Phys Med Rehabil Clin N Am. 2018;29(1):73-92. doi:10.1016/j.pmr.2017.08.007

6. Zhai J, Zhang L, Li M, et al. Epidural injection with or without steroid in managing chronic low-back and lower extremity pain: a meta-analysis of 10 randomized controlled trials. Am J Ther. 2017;24 (3):e259-e69. doi:10.1097/MJT.0000000000000265

7. Shamliyan TA, Staal JB, Goldmann D, et al. Epidural steroid injections for radicular lumbosacral pain: a systematic review. Phys Med Rehabil Clin N Am. 2014;25(2):471-89 e1-50. doi:10.1016/j. pmr.2014.02.001

8. Wong SSC, Qiu Q, Cheung CW. Segmental spinal myoclonus complicating lumbar transforaminal epidural steroid injection. Reg Anesth Pain Med. 2018;43(5):554-556. doi:10.1097/AAP.000000000000 0742
9. Makkar JK, Gourav KKP, Jain K, et al. Transforaminal versus lateral parasagittal versus midline interlaminar lumbar epidural steroid injection for management of unilateral radicular lumbar pain: a randomized double-blind trial. Pain Physician. 2019;22 (6):561-573.

10. Wang T, Wang H, Yang DL, et al. Factors predicting surgical site infection after posterior lumbar surgery: A multicenter retrospective study. Medicine (Baltimore). 2017;96(5):e6042. doi:10.1097/ MD.0000000000006042

11. Singla A, Yang S, Werner BC, et al. The impact of preoperative epidural injections on postoperative infection in lumbar fusion surgery. J Neurosurg Spine. 2017;26(5):645-649. doi:10.3171/ 2016.9.SPINE16484

12. Seavey JG, Balazs GC, Steelman T, et al. The effect of preoperative lumbar epidural corticosteroid injection on postoperative infection rate in patients undergoing single-level lumbar decompression. Spine J. 2017;17(9):1209-1214. doi:10.1016/j.spinee.2017.04.003

13. Brown TS. Intra-articular injections should be avoided in the 3 months prior to total knee arthroplasty: commentary on an article by Shawn S. Richardson, MD, et al.: "Comparison of infection risk with corticosteroid or hyaluronic acid injection prior to total knee arthroplasty". J Bone Joint Surg Am. 2019;101(2):e8.

14. Donnally CJ 3rd, Rush AJ 3rd, Rivera S, et al. An epidural steroid injection in the 6 months preceding a lumbar decompression without fusion predisposes patients to post-operative infections. J Spine Surg. 2018;4(3):529-533. doi:10.21037/jss.2018.09.05

15. Yang S, Werner BC, Cancienne JM, et al. Preoperative epidural injections are associated with increased risk of infection after single-level lumbar decompression. Spine J. 2016;16(2):191-196. doi:10.1016/j.spinee.2015.07.439

16. Richardson SS, Schairer WW, Sculco TP, et al. Comparison of infection risk with corticosteroid or hyaluronic acid injection prior to total knee arthroplasty. J Bone Joint Surg Am. 2019;101 (2):112-118. doi:10.2106/JBJS.18.00454

17. Schairer WW, Nwachukwu BU, Mayman DJ, et al. Preoperative hip injections increase the rate of periprosthetic infection after total hip arthroplasty. J Arthroplasty. 2016;31(9 Suppl):166-69 e1. doi:10.1016/j.arth.2016.04.008

18. Lee Y, Kim JS, Kim JY. Cervical meningomyelitis after lumbar epidural steroid injection. Ann Rehabil Med. 2015;39(3):504-507. doi:10.5535/arm.2015.39.3.504

19. Schneider BJ, Maybin S, Sturos E. Safety and complications of cervical epidural steroid injections. Phys Med Rehabil Clin N Am. 2018;29(1):155-169. doi:10.1016/j.pmr.2017.08.012

20. Kraeutler MJ, Bozzay JD, Walker MP, et al. Spinal subdural abscess following epidural steroid injection. J Neurosurg Spine. 2015;22 (1):90-93. doi:10.3171/2014.9.SPINE14159

21. Annane D, Renault A, Brun-Buisson C, et al. Hydrocortisone plus fludrocortisone for adults with septic shock. $N$ Engl J Med. 2018;378 (9):809-818. doi:10.1056/NEJMoa1705716

22. Lee JH, Kim DH, Kim DH, et al. Comparison of clinical efficacy of epidural injection with or without steroid in lumbosacral disc herniation: a systematic review and meta-analysis. Pain Physician. 2018;21 (5):449-468. doi:10.36076/ppj.2018.5.449

23. Gerometta A, Rodriguez Olaverri JC, Bitan F. Infections in spinal instrumentation. Int Orthop. 2012;36(2):457-464. doi:10.1007/ s00264-011-1426-0 
Journal of Pain Research

Dovepress

\section{Publish your work in this journal}

The Journal of Pain Research is an international, peer reviewed, open access, online journal that welcomes laboratory and clinical findings in the fields of pain research and the prevention and management of pain. Original research, reviews, symposium reports, hypothesis formation and commentaries are all considered for publication. The manuscript management system is completely online and includes a very quick and fair peer-review system, which is all easy to use. Visit http:// www.dovepress.com/testimonials.php to read real quotes from published authors.

Submit your manuscript here: https://www.dovepress.com/journal-of-pain-research-journal 